\title{
Valores nutricionais do milho de diferentes qualidades para frangas de reposição na fase de recria
}

\author{
[Nutritional value of corn with different qualities for egg pullets \\ in the growing phase] \\ G.S.C.P. Corte Real ${ }^{1}$, H.P. Couto ${ }^{2}$, M.B. Matos ${ }^{1}$, M.S. Lyra ${ }^{4}$, \\ A.V.C. Gomes ${ }^{3}$, S.R.R. Ferreira ${ }^{4}$ \\ ${ }^{1}$ Aluna de pós-graduação - Universidade Estadual do Norte Fluminense - Campos dos Goytacazes, RJ \\ ${ }^{2}$ Universidade Estadual do Norte Fluminense - Campos dos Goytacazes, RJ \\ ${ }^{3}$ Universidade Federal Rural do Rio de Janeiro - Seropédica, RJ \\ ${ }^{4}$ Autônomo
}

\section{RESUMO}

O experimento objetivou determinar os valores nutricionais de diferentes frações de milho obtidas por meio de estratificação em mesa densimétrica na recria de frangas. Os milhos foram designados como: MDA - milho de densidade alta; MDI - milho de densidade intermediária; MDB - milho de densidade baixa; MDT - milho de densidade total, composto de 30\% de MDA, 60\% de MDI e 10\% de MDB. Para a determinação da energia metabolizável corrigida (EMAn) foi utilizado o método de coleta total de excretas em frangas Hy Line de 15 semanas. Os valores de EMAn ( $\mathrm{kcal} / \mathrm{kg}$ na MN) foram: $3.467 ; 3.340 ; 3.217$ e $3.385 \mathrm{kcal} / \mathrm{kg}$ e densidade $\left(\mathrm{kg} / \mathrm{m}^{3}\right): 818,61 ; 698,13 ; 681,80$ e $736,39 \mathrm{~kg} / \mathrm{m}^{3}$ para MDA; MDI; MDB e MDT, respectivamente. O MDB apresentou maior valor em todos os aminoácidos digestíveis, com maior intensidade para o triptofano. As frações de milho foram variáveis quanto ao EMAn e perfil de aminoácidos digestíveis, indicando a necessidade de correções nutricionais para a formulação de rações de custo mínimo.

Palavras-chave: coeficiente de metabolizabilidade, energia metabolizável, micotoxina e mesa densimétrica

\begin{abstract}
The experiment aimed to determine the nutritional value of different corn fractions obtained by stratification in a gravity table of replacement pullets. The corn was designated as MDA - high density corn; MDI - medium density corn; $M D B$ - low density corn; MDT - total corn density, composed of 30\% MDA, 60\% MDI and 10\% $M D B$. To determine the corrected metabolizable energy $\left(A M E_{N}\right)$ a method for total collection of excreta with pullets Hy Line was used for 15 weeks. AME $E_{N}$ (kcal/kg in MN) were: 3467, 3340, 3217 and $3385 \mathrm{kcal} / \mathrm{kg}$ and density $\left(\mathrm{kg} / \mathrm{m}^{3}\right):$ 818.61, 698.13, 681.80 and 736.39 for MDA, MDI, MDB and MDT, respectively. The MDB showed the highest value in all the digestible amino acids, with higher intensity for the tryptophan. The fractions of corn were variable as to $A M E_{N}$ and digestible amino acid profiles, indicating the need for corrections to the nutritional feed formulation of minimum cost.
\end{abstract}

Keywords: coefficient metabolizability; metabolizable energy; micotoxin and gravity table

\section{INTRODUÇÃO}

Dietas comumente usadas na avicultura de postura têm o milho como principal ingrediente e fonte de energia.

Segundo Lima (2001), no Brasil o mercado de milho valoriza pouco a qualidade, pois o pagamento diferenciado, premiando esse atributo, é pouco significativo. O que está à venda é a quantidade e não a qualidade (valor nutricional, ausência de micotoxinas, entre outros). Porém, nos grãos de má qualidade, o valor nutricional pode ter alteração da composição química, diminuição da biodisponibilidade de alguns nutrientes, presença

Recebido em 5 de julho de 2012

Aceito em 3 de setembro de 2013

E-mail: gabrielapamplona@yahoo.com.br 
de fatores antinutricionais e proliferação de fungos com ou sem a produção de micotoxinas (Rostagno, 1993).

Um problema a ser considerado é que as rações são formuladas com base nos valores descritos em tabelas de composição de alimentos. A composição média do milho nas tabelas pode diferir da composição do milho utilizado e, consequentemente, as dietas fornecidas podem extrapolar as exigências nutricionais dos animais.

Os conhecimentos da composição química e dos valores energéticos do milho podem permitir a elaboração de equações de predição que permitam estimativas mais exatas do valor energético do milho a partir de sua composição química, classificação e densidade. Dessa forma, neste trabalho, estudaram-se os valores nutricionais de milhos de quatro qualidades para frangas de postura na fase de recria.

\section{MATERIAL E MÉTODOS}

O ensaio biológico foi realizado no setor de avicultura da Unidade de Apoio à Pesquisa do Laboratório de Zootecnia e Nutrição Animal da Universidade Estadual do Norte Fluminense, localizada em Campos dos Goytacazes, Rio de Janeiro. Os valores de energia metabolizável aparente (EMA) e aparente corrigida (EMAn) foram determinados utilizando-se $\mathrm{o}$ método tradicional de coleta total de excretas. Avaliaram-se quatro tipos de milho, três originados diretamente da estratificação dos grãos em mesa densimétrica (Zampronio, Modelo Z-75): MDA - milho de densidade alta; MDI - milho de densidade intermediária; MDB - milho de densidade baixa; e MDT - milho de densidade total, fração composta de $30 \%$ de MDA, $60 \%$ de MDI e 10\% de MDB, utilizada para simular a composição do milho não estratificado pela mesa densimétrica. A estratificação dos grãos foi realizada na fábrica de rações da Reginaves Indústria e Comércio de Aves Ltda. (RICA), localizada no estado do Rio de Janeiro.

Para elaboração da matriz nutricional dos milhos de diferentes qualidades, realizou-se uma série de análises bromatológicas para determinação dos valores de matéria seca (MS), proteína bruta $(\mathrm{PB})$, extrato etéreo (EE), fibra bruta $(\mathrm{FB})$, matéria mineral (MM), extrato não-nitrogenado
(ENN), cálcio $(\mathrm{Ca})$, fósforo total $(\mathrm{Pt})$ e fósforo disponível $(\mathrm{Pd})$. Os perfis de aminoácidos digestíveis foram analisados pelo método de Espectroscopia de Refletância no Infravermelho Próximo (NIRs), realizado pelo Laboratório CEAN - ADISSEO, segundo curvas-padrão propostas pelo Rhodimet ${ }^{\mathrm{TM}}$ NIRSA. O método da fatoração foi utilizado para corrigir os níveis de aminoácidos digestíveis da matriz nutricional dos milhos de diferentes qualidades, por meio da relação entre eles e a proteína bruta, obtidas pelas análises no NIRs.

A densidade dos milhos foi avaliada utilizandose a metodologia do peso hectolítrico no medidor de peso hectolítrico, modelo The easy-way, pela qual os produtos são diferenciados pela mesa densimétrica, que estratifica o cereal pela densidade ou pelo peso específico. Baidoo et al. (1991) apresentaram a equação de predição para a estimativa da EMAn $(\mathrm{kcal} / \mathrm{kg})=2,929+$ $0,01088 \times$ densidade $(\mathrm{kg} / \mathrm{hL})$ de diferentes lotes de milho. Essa equação foi utilizada para estimar o valor energético, com as densidades e as matérias secas obtidas dos milhos estudados.

Utilizando os padrões do Ministério da Agricultura, Pecuária e Abastecimento (Brasil, 1976), foram realizadas análises físicas de classificação de grãos de três amostras das diferentes frações no Laboratório de Análises de Alimentos da Guaraves Alimentos, Guarabira, PB, considerando: grãos quebrados, ardidos, carunchados e chochos, impurezas e fragmentos e materiais estranhos. Os resultados da classificação foram utilizados para estimar os valores energéticos das diferentes frações através de equações de predição, apresentadas na literatura e comparadas aos resultados obtidos no ensaio de metabolismo energético.

O ensaio de metabolismo foi realizado utilizando-se o método de coleta total de excretas em frangas de reposição na fase de recria (15 semanas de idade). Foram utilizados os milhos de diferentes qualidades, que substituíram em $40 \%$ uma dieta-referência à base de milho e farelo de soja, formulada para satisfazer às exigências das aves na fase. As exigências das aves e a composição química dos alimentos, com exceção dos diferentes milhos estudados, foram determinadas com base nas Tabelas Brasileiras para Aves e Suínos (Rostagno et al., 2005) e Manual da linhagem 
(Hy Line, 2008). O ensaio teve duração de dez dias, sendo cinco de adaptação das aves às instalações e às rações experimentais, e cinco de coleta total das excretas. O ensaio foi conduzido com 75 frangas da linhagem comercial Hy Line W-36 com 15 semanas de idade, com peso de $880 \mathrm{~g}( \pm 74 \mathrm{~g})$, provenientes de granja comercial. Foram distribuídas três aves/unidade experimental, com cinco tratamentos e cinco repetições. As excretas diariamente coletadas foram acondicionadas em sacos plásticos devidamente identificados e armazenadas em freezer até o final do período. Posteriormente, as amostras foram descongeladas, pesadas e homogeneizadas para retirada de subamostras para análises laboratoriais.

Ao final do ensaio, foram realizadas as análises bromatológicas dos ingredientes, rações e excretas para determinação de matéria seca (MS), nitrogênio total $(\mathrm{N})$ e energia bruta (EB), de acordo com as metodologias descritas por Silva e Queiroz (2002), no Laboratório de Zootecnia e Nutrição Animal LZNA/CCTA/UENF.

As análises de energia bruta foram realizadas na Universidade Federal Rural do Rio de Janeiro (UFRRJ) utilizando bomba calorimétrica (Modelo Parr 1341) e, com base nos resultados em conjunto com o consumo de ração e produção das excretas, foi determinada a energia metabolizável aparente (EMA), energia metabolizável aparente corrigida (EMAn) e coeficiente de metabolizabilidade da energia bruta (CMAEB) utilizando as equações propostas por Matterson et al. (1965).

Os tratamentos consistiram em uma raçãoreferência, conforme Tabela 1, e de quatro outras rações, obtidas pela substituição de $40 \%$ da ração-referência pelos milhos de densidade alta (MDA), intermediária (MDI), baixa (MDB) e de densidade total (MDT).

Tabela 1. Composição percentual da ração-referência fornecida às frangas de reposição na fase de recria (15 semanas)

\begin{tabular}{lc}
\hline Ingredientes (\%) & Ração experimental \\
\hline Milho & 75,87 \\
Farelo de soja & 19,27 \\
Calcário & 2,36 \\
Fosfato Bicálcico & 1,65 \\
Sal (NaCl) & 0,35 \\
Suplemento mineral e vitamínico ${ }^{2}$ & 0,50 \\
\hline Total & 100,00 \\
\hline Nível nutricional calculado & \\
\hline Energia metabolizável (kcal/kg) & 3.000 \\
Proteína Bruta (\%) & 15,00 \\
Lisina digestível (\%) & 0,651 \\
Metionina digestível (\%) & 0,320 \\
Metionina + cistina digestível (\%) & 0,551 \\
Cálcio (\%) & 1,379 \\
Fósforo disponível (\%) & 0,400 \\
Sódio (\%) & 0,158 \\
\hline
\end{tabular}

${ }^{1}$ Composição calculada segundo Rostagno et al. (2005); ${ }^{2}$ Níveis de garantia por kg do produto: vit. A - 1.500.000UI; vit. $\mathrm{D}_{3}-500.000 \mathrm{UI}$; vit. $\mathrm{E}-1.000 \mathrm{mg}$; vit. $\mathrm{K}_{3}-300 \mathrm{mg}$; vit. $\mathrm{B}_{1}$ (Tiamina) - 200mg; vit. $\mathrm{B}_{2}$ (Riboflavina) - 900mg; vit. $\mathrm{B}_{6}$ (Piridoxina) - 300mg; vit. $\mathrm{B}_{12}$ (cobalamina) - 2.000mcg; ácido fólico - 100mg; biotina - 5mg, niacina $3.600 \mathrm{mg}$; pantotenato de cálcio $-1.200 \mathrm{mg}$; cobre $-1.200 \mathrm{mg}$; ferro $-6.500 \mathrm{mg}$; iodo $-240 \mathrm{mg}$; manganês 12.000mg; selênio - 40mg; zinco - 9.000mg; cloreto de colina - 33g; metionina $-174 \mathrm{~g}$; antioxidante $-1.000 \mathrm{mg}$ e promotor de eficiência alimentar $-4.000 \mathrm{mg}$.

Nos milhos e nas rações experimentais foram realizadas análises das micotoxinas: aflatoxina e tricotecenos - T2 utilizando ensaio ELISA (Enzyme-linked Immunosorbent Assay) marca Neogem no Laboratório de Análises de
Alimentos da Guaraves Alimentos, Guarabira, PB.

O delineamento utilizado foi o modelo inteiramente casualizado, e os dados foram 
submetidos à análise utilizando o programa computacional de análises estatísticas SAEG 9.1 (UFV, 2007).

\section{RESULTADOS E DISCUSSÃO}

De acordo com os dados analisados, ocorreram diferenças entre os valores de EMA e EMAn entre os tipos de milho estudados, conforme Tabela 2, o que está relacionado às variações na sua composição bromatológica.
Os valores de EMA foram em média 2,55\% superiores aos de EMAn, uma característica observada quando os valores de EM são determinados em aves em crescimento, pois ocorre retenção de nitrogênio pelas aves para que ocorra deposição de tecido protéico, acontecendo assim um balanço de nitrogênio positivo. EMA e a EMAn decresceram à medida que a densidade do milho reduziu, refletindo sua pior qualidade.

Tabela 2: Valores médios e erro padrão de energia metabolizável aparente (EMA), energia metabolizável aparente corrigida por retenção de nitrogênio (EMAn) e coeficiente de metabolização aparente da energia bruta (CMAEB) dos milhos de diferentes qualidades para frangas de reposição na fase de recria

\begin{tabular}{lcccc} 
& MDA $^{1}$ & MDI $^{2}$ & \multicolumn{1}{c}{ MDB $^{3}$} & MDT $^{4}$ \\
\hline EMA (Kcal/kg MS) & $4003( \pm 56,64) \mathrm{a}$ & $3872( \pm 61,16) \mathrm{a}$ & $3704( \pm 78,76) \mathrm{b}$ & $3910( \pm 116,02) \mathrm{a}$ \\
EMAn (Kcal/kg MS) & $3907( \pm 56,00) \mathrm{a}$ & $3768( \pm 52,85) \mathrm{b}$ & $3617( \pm 46,76) \mathrm{c}$ & $3801( \pm 109,10) \mathrm{b}$ \\
EMA (Kcal/kg MN) & $3552( \pm 50,27) \mathrm{a}$ & $3432( \pm 54,21) \mathrm{b}$ & $3295( \pm 69,85) \mathrm{c}$ & $3482( \pm 97,16) \mathrm{ab}$ \\
EMAn (Kcal/kg MN) & $3467( \pm 49,70) \mathrm{a}$ & $3340( \pm 46,85) \mathrm{b}$ & $3217( \pm 41,59) \mathrm{c}$ & $3385( \pm 97,16) \mathrm{ab}$ \\
CMAEB (\%) & $87,37( \pm 1,19) \mathrm{a}$ & $85,26( \pm 1,28) \mathrm{ab}$ & $83,67( \pm 1,68) \mathrm{c}$ & $87,38( \pm 2,47) \mathrm{a}$ \\
\hline \multicolumn{2}{l}{ Médias seguidas de letras distintas na linha diferem entre si segundo o Teste de Newman Keuls $(\mathrm{P}<0,05)}$. \\
${ }^{1} \mathrm{MDA}$ - milho de densidade alta; ${ }^{2}$ MDI - milho de densidade intermediária; ${ }^{3} \mathrm{MDB}-$ milho de densidade baixa e \\
${ }^{4} \mathrm{MDT}-$ milho de densidade total composto de 30\% de MDA, 60\% de MDI e 10\% de MDB.
\end{tabular}

Os valores de EMAn são utilizados diretamente na formulação de rações de aves. Considerando a média dos valores de EMAn das frações de milho estudadas, verificou-se que MDA e MDT foram superiores aos relatados por Tabelas Brasileiras de Aves e Suínos (2005), e os valores do MDI e MDB foram inferiores aos valores obtidos pelos autores, que é de $3.381 \mathrm{kcal} / \mathrm{kg}$ de $\mathrm{MN}$.

O MDB apresentou valor energético inferior $(\mathrm{P}<0,05)$ às demais frações de milho, considerando tanto a EMA e a EMAn, com EMAn (kcal/kg de MN) 250kcal inferior ao MDA, considerada a fração com maior valor energético. O MDT não diferiu do MDA e do MDI para EMAn (kcal/kg de MN). O MDT, que simula a composição do milho não estratificado pela mesa densimétrica, apresentou valores de energia semelhantes ao MDI. Esses resultados comprovam a eficiência da estratificação pela mesa densimétrica.

Os valores de EMAn (kcal/kg de MS) do MDA e MDT foram superiores e do MDI e MDB foram inferiores ao valor citado pela Tabela de Janssen (1989), que é de $3.783 \mathrm{kcal} / \mathrm{kg}$ de MS. Pozza et al. (2006) analisaram amostras de milho para poedeiras em fase de produção - 24 semanas - e citaram valores de EMA e EMAn médios de 3.374 e $3.269 \mathrm{kcal} / \mathrm{kg}$ de $\mathrm{MS}$, respectivamente, valores inferiores aos encontrados neste experimento. Porém, Silva et al. (2009) relataram $3.384 \mathrm{kcal} / \mathrm{kg}$ de $\mathrm{MN}$ de EMAn para milhos fornecidos para poedeiras com 41 semanas de idade, com CMAEB de 87,38\%.

O CMAEB representa o quanto da EB do alimento é metabolizado pelo animal. Segundo Conte et al. (2002), a energia metabolizável é afetada direta e positivamente pela composição do alimento em amido, gordura e proteína, e negativamente pelos carboidratos estruturais. $\mathrm{O}$ milho, por ser rico em amido e com baixos valores de carboidratos estruturais, apresenta um coeficiente de metabolizabilidade alto.

O MDB apresentou um aproveitamento menor em 4,2\% (p<0,05) quando comparado ao MDA. Entretanto, em todas as frações de milho, os valores de CMAEB encontrados foram superiores a $70 \%$. As diferenças entre os valores energéticos dos milhos de diferentes qualidades determinadas em poedeiras na fase de crescimento sugerem a necessidade de avaliação da energia metabolizável de vários outros alimentos importantes na alimentação dessas aves. Futuramente, as tabelas de composição 
nutricional apresentarão os valores energéticos dos alimentos de acordo com a categoria das aves e as fases de criação.

A composição bromatológica encontrada para as frações de milho neste estudo, comparada com os dados da literatura, tanto nas tabelas nacionais Rostagno et al. (2005) e EMBRAPA (1991), quanto em tabela estrangeira (Nutrient..., 1994), apresentou variações entre os valores de composição química das frações (MDA, MDI, MDB e MDT) e os daquelas referências. Tais variações podem ser causadas por vários fatores, tais como: material genético, diferença entre os solos, adubação, clima, tipos de armazenamento (Tab. 3).

Tabela 3. Composição bromatológica dos milhos de diferentes qualidades

\begin{tabular}{lccccc}
\hline \multicolumn{1}{c}{ Nutrientes\% } & & MDA $^{1}$ & MDI $^{2}$ & MDB $^{3}$ & MDT $^{4}$ \\
\hline PB & $\%$ & $7,85 \mathrm{~b}$ & $7,06 \mathrm{~b}$ & $9,43 \mathrm{a}$ & $7,45 \mathrm{~b}$ \\
$\mathrm{EE}$ & $\%$ & $4,61 \mathrm{a}$ & $3,26 \mathrm{~b}$ & $3,91 \mathrm{~b}$ & $3,78 \mathrm{~b}$ \\
$\mathrm{FB}$ & $\%$ & $2,22 \mathrm{~b}$ & $4,01 \mathrm{a}$ & $2,26 \mathrm{~b}$ & $1,16 \mathrm{bc}$ \\
MM & $\%$ & $1,17 \mathrm{a}$ & $1,95 \mathrm{a}$ & $1,43 \mathrm{a}$ & $1,16 \mathrm{a}$ \\
ENN $^{5}$ & $\%$ & $73,23 \mathrm{a}$ & $72,62 \mathrm{a}$ & $71,92 \mathrm{a}$ & $74,86 \mathrm{a}$ \\
Cálcio & $\%$ & $0,06 \mathrm{a}$ & $0,06 \mathrm{a}$ & $0,09 \mathrm{a}$ & $0,11 \mathrm{a}$ \\
P total & $\%$ & $0,19 \mathrm{a}$ & $0,18 \mathrm{a}$ & $0,21 \mathrm{a}$ & $0,19 \mathrm{a}$ \\
P disp. & $\%$ & $0,06 \mathrm{a}$ & $0,06 \mathrm{a}$ & $0,07 \mathrm{a}$ & $0,06 \mathrm{a}$ \\
\hline
\end{tabular}

Médias seguidas de letras distintas na linha diferem entre si segundo o Teste de Newman Keuls $(\mathrm{p}<0,05)$.

${ }^{1} \mathrm{MDA}$ - milho de densidade alta; ${ }^{2} \mathrm{MDI}$ - milho de densidade intermediária; ${ }^{3} \mathrm{MDB}$ - milho de densidade baixa e ${ }^{4}$ MDT - milho de densidade total composto de 30\% de MDA, 60\% de MDI e $10 \%$ de MDB.

${ }^{5} \mathrm{ENN}($ Extrato não nitrogenado $)=100-(\mathrm{UM}+\mathrm{PB}+\mathrm{EE}+\mathrm{MM}+\mathrm{FB}) ;{ }^{6} \mathrm{P}$ disponível: fósforo disponível $=$ calculado pelo fator de correção obtido nas Tabelas Brasileiras de Aves e Suínos (2005); PB: proteína bruta; EE: extrato etéreo; FB: fibra bruta; MM: matéria mineral; P total: fósforo total.

Os valores de proteína bruta nos milhos de diferentes qualidades variaram em até $25 \%(7,06$ a $9,43 \%$ ). O MDB teve maior teor proteico que as demais frações de milho. O milho de baixa densidade apresentou maior conteúdo de proteína (9,3 vs 8,4\%), entretanto isso não resultou em aumento no teor de aminoácidos essenciais nas rações de aves (metionina+cistina e lisina). Lopes et al. (1988) avaliaram a perda de peso e mudanças na composição química do milho e verificaram que, à medida que aumentou o ataque de pragas e fungos, os grãos tiveram perda de peso, redução do peso/volume, aumento no teor proteico, redução no seu valor energético e aumento de alguns aminoácidos essenciais. O percentual de aminoácidos digestíveis das diferentes frações de milho é apresentado na Tabela 4.

Tabela 4. Percentuais de aminoácidos das frações de milho analisados pelo NIRs (Espectroscopia de Refletância no Infravermelho Próximo), segundo curvas padrão propostas pelo Rhodimet ${ }^{\mathrm{TM}}$ NIRSA

\begin{tabular}{lccccc}
\hline \multicolumn{1}{c}{ Nutriente } & Unidade & $\mathrm{MDA}^{1}$ & $\mathrm{MDI}^{2}$ & $\mathrm{MDB}^{3}$ & $\mathrm{MDT}^{4}$ \\
\hline Lisina & $\%$ & $0,167 \mathrm{~b}$ & $0,177 \mathrm{c}$ & $0,220 \mathrm{a}$ & $0,170 \mathrm{~b}$ \\
Metionina & $\%$ & $0,143 \mathrm{~b}$ & $0,127 \mathrm{c}$ & $0,167 \mathrm{a}$ & $0,137 \mathrm{bc}$ \\
Cistina & $\%$ & $0,150 \mathrm{~b}$ & $0,130 \mathrm{~d}$ & $0,160 \mathrm{a}$ & $0,137 \mathrm{c}$ \\
Metionina+cistina & $\%$ & $0,293 \mathrm{~b}$ & $0,257 \mathrm{~d}$ & $0,327 \mathrm{a}$ & $0,273 \mathrm{c}$ \\
Treonina & $\%$ & $0,183 \mathrm{~b}$ & $0,163 \mathrm{c}$ & $0,267 \mathrm{a}$ & $0,167 \mathrm{c}$ \\
Triptofano & $\%$ & $0,040 \mathrm{~b}$ & $0,040 \mathrm{~b}$ & $0,077 \mathrm{a}$ & $0,040 \mathrm{~b}$ \\
Valina & $\%$ & $0,287 \mathrm{~b}$ & $0,270 \mathrm{c}$ & $0,400 \mathrm{a}$ & $0,283 \mathrm{~b}$ \\
Isoleucina & $\%$ & $0,197 \mathrm{~b}$ & $0,177 \mathrm{~b}$ & $0,310 \mathrm{a}$ & $0,190 \mathrm{~b}$ \\
Leucina & $\%$ & $0,890 \mathrm{c}$ & $0,880 \mathrm{c}$ & $1,247 \mathrm{a}$ & $0,903 \mathrm{~b}$ \\
Fenilalanina & $\%$ & $0,297 \mathrm{~b}$ & $0,280 \mathrm{c}$ & $0,450 \mathrm{a}$ & $0,293 \mathrm{~b}$ \\
Histidina & $\%$ & $0,193 \mathrm{~b}$ & $0,167 \mathrm{~d}$ & $0,213 \mathrm{a}$ & $0,180 \mathrm{c}$ \\
Arginina & $\%$ & $0,320 \mathrm{~b}$ & $0,303 \mathrm{c}$ & $0,390 \mathrm{a}$ & $0,307 \mathrm{c}$ \\
\hline
\end{tabular}

Médias seguidas de letras distintas na linha diferem entre si segundo o Teste de Newman Keuls $(\mathrm{p}<0,05)$.

${ }^{1}$ MDA - milho de densidade alta; ${ }^{2} \mathrm{MDI}$ - milho de densidade intermediária; ${ }^{3} \mathrm{MDB}$ - milho de densidade baixa e ${ }^{4} \mathrm{MDT}$ - milho de densidade total, composto de 30\% de MDA, 60\% de MDI e $10 \%$ de MDB. 
O perfil dos aminoácidos digestíveis no MDB foi maior $(p<0,05)$ que nas demais frações de milho. Verificou-se que o aminoácido que aumentou de forma mais intensa foi o triptofano, com média de $92,5 \%$ em relação aos demais milhos. Com relação aos principais aminoácidos limitantes para poedeiras: metionina+cistina, lisina e treonina, estes foram em média 19,5; 28,5 e $56,5 \%$, respectivamente, superiores no MDB em relação às demais frações de milho. A metionina é o primeiro aminoácido limitante em rações avícolas, e sua suplementação em dietas de poedeiras resulta em aumento na eficiência de utilização da proteína. Segundo Narváez-Solarte (1996), níveis de metionina+cistina $(\mathrm{M}+\mathrm{C})$ influenciam o peso de ovos, ocorrendo aumento no peso com aumento dos níveis de $\mathrm{M}+\mathrm{C}$ total na ração; já a lisina é o segundo aminoácido limitante e seu interesse na alimentação de poedeiras pode afetar a deposição de proteína corporal (Valério et al., 2003) e dos ovos (Ribeiro et al., 2002), além do teor de sólidos totais (Novak et al., 2004), e, possivelmente, melhorar as propriedades funcionais do ovo como matéria-prima para a indústria alimentícia.

Os resultados de densidade para os diferentes tipos de milho (MDA, MDI, MDB e MDT), utilizando-se o método do peso hectolítrico, foram: 818,$61 ; 698,13 ; 681,80$ e $736,39 \mathrm{~kg} / \mathrm{m}^{3}$, respectivamente. A média da densidade para o MDA foi 10,$04 ; 14,72$ e $16,71 \%$ superiores às densidades observadas para o MDT, MDI e MDB, respectivamente. Leeson et al. (1976) avaliaram a relação entre a densidade do grão e valores de energia metabolizável aparente (EMA) e verificaram que o decréscimo de $20 \%$ da densidade do grão está associado à redução de $4,3 \%$ no valor de EMA. Este estudo indica que a densidade do milho está relacionada aos conteúdos de EMA, entretanto as variações de EMA são baixas quando comparadas às grandes variações de densidade.

Pereira et al. (2009) também estudaram milhos com duas densidades $\left(<650 \mathrm{~kg} / \mathrm{m}^{3}\right.$ e $\left.>750 \mathrm{~kg} / \mathrm{m}^{3}\right)$ estratificados por mesa densimétrica e relataram que o milho que apresentou densidade inferior a $650 \mathrm{~kg} / \mathrm{m}^{3}$ apresenta menores níveis de EMA $(3.826 \mathrm{kcal} / \mathrm{kg}$ vs $3.956 \mathrm{kcal} / \mathrm{kg})$ e maiores níveis de PB (9,0\% vs 8,5\%), com aumento do valor de lisina $(0,29$ vs 0,22), quando comparado com o milho de densidade superior a $750 \mathrm{~kg} / \mathrm{m}^{3}$. Resultados semelhantes foram descritos por Baidoo et al. (1991), que avaliaram grãos de milho na alimentação de aves variando a densidade de 72 a $60 \mathrm{~kg} / \mathrm{hL}$. A redução da densidade foi associada a aumentos lineares da proteína e da fibra e diminuição do amido e de energia. Os autores apresentaram uma equação de predição para a estimativa da EMAn $(\mathrm{kcal} / \mathrm{kg})=2,929+0,01088 \times$ Densidade $(\mathrm{kg} / \mathrm{hL})$.

Utilizando essa equação para estimar o valor energético com as densidades e matérias secas obtidas das frações de milho estratificado, obteve-se o resultado estimado de 3.390, 3.270, 3.265 e $3.322 \mathrm{kcal} / \mathrm{kg}$ EMAn para o MDA, MDI, MDB e MDT, respectivamente. Esses valores, comparados aos obtidos pelo ensaio metabólico, são inferiores aos valores de MDA, MDI e MDT e superiores aos encontrados para MDB. A equação parece subestimar o valor energético para frações de milho de alta densidade e densidade intermediária e superestimar os de mais baixa densidade.

A classificação dos milhos, conforme a Tabela 5, mostrou maiores incidências de grãos quebrados e impureza/fragmentos no MDB, que indicou um produto de pior qualidade nutricional, explicando as grandes perdas de EM obtidas no ensaio de metabolismo.

A partir dos resultados de classificação obtidos neste trabalho, foram estimados os valores das perdas de energia metabolizável (EMp) das frações considerando os resultados da classificação utilizando a equação $\mathrm{EMp}=-0,064$ + 1,62 QBR + 6,98 FRIM + 10,06 FUN + 12,28 INS + 5,87 ADC, proposta por Rostagno et al. (2005), apresentado na Tabela 6, em que: EMp = Energia Metabolizável Perdida para Aves (kcal/kg); QBR = Grãos Quebrados (\%); FRIM = Fragmentos de Grãos e Impurezas (\%); FUN $=$ Grãos atacados por fungos (\%); INS = Grãos atacados por insetos (\%); $\mathrm{ADC}=$ Grãos atacados por Diversas Causas (\%). 


\section{Corte Real et al.}

Tabela 5. Classificação das diferentes frações de milho estratificado pela mesa densimétrica de acordo com Brasil (1976)

\begin{tabular}{lcccc}
\hline Classificação & MDA & MDI & MDB & MDT \\
\hline Quebrados (\%) & 5,13 & 22,65 & 46,87 & 17,28 \\
Ardidos (\%) & 4,85 & 4,48 & 1,47 & 6,94 \\
Carunchados (\%) & 1,89 & 3,69 & 0,63 & 2,83 \\
Chochos (\%) & 0,25 & 1,35 & 2,64 & 1,21 \\
Impureza/ Fragmento (\%) & 0,29 & 0,96 & 41,79 & 5,00 \\
Material Estranho (\%) & 0,20 & 2,00 & 2,76 & 1,43 \\
\hline Total de defeitos (\%) & 12,61 & 35,13 & 96,16 & 34,69 \\
\hline
\end{tabular}

MDA - milho de densidade alta; MDI - milho de densidade intermediária; MDB - milho de densidade baixa e MDT - milho de densidade total, composto de 30\% de MDA, 60\% de MDI e 10\% de MDB.

Tabela 6. Estimativa de perdas do valor energético $(\mathrm{kcal} / \mathrm{kg})$ das frações de milho com base na equação desenvolvida por Rostagno et al. (2005)

\begin{tabular}{lcccc}
\hline & MDA $^{1}$ & MDI $^{2}$ & MDB $^{3}$ & MDT $^{4}$ \\
\hline Quebrados & \multicolumn{4}{c}{$(\mathrm{kcal} / \mathrm{kg})$} \\
Ardidos & 8,31 & 36,69 & 75,93 & 27,99 \\
Carunchados & 48,79 & 45,07 & 14,82 & 69,78 \\
Chochos & 23,17 & 45,35 & 7,70 & 34,75 \\
Impureza/ Fragmentos & 1,77 & 9,40 & 18,45 & 8,42 \\
Material Estranho & 2,02 & 6,72 & 291,67 & 34,90 \\
\hline EMp & 1,17 & 11,72 & 16,22 & 8,39 \\
\hline EMp: energia metabolizável perdida para aves (kcal/kg). & ${ }^{1}$ MDA - milho de densidade alta; ${ }^{2}$ MDI - milho de \\
densidade intermediária; ${ }^{3} \mathrm{MDB}-$ milho de densidade baixa e e & ${ }^{4} \mathrm{MDT}-$ milho de densidade total, composto de 30\% de \\
MDA, 60\% de MDI e 10\% de MDB. & \multicolumn{4}{c}{}
\end{tabular}

As perdas de energia metabolizável (EM) dos grãos chochos e fragmento/impureza foram consideradas como FRIM, perdas de EM dos grãos ardidos foram consideradas como FUN, perdas de EM dos grãos carunchados foram consideradas como INS e perdas de EM dos grãos com material estranho foram consideradas como ADC.

Observou-se que os valores energéticos obtidos a partir da equação de predição de Rostagno $e t$ al. (2005), na Tab. 7, foram inferiores aos observados neste experimento para frangas de reposição na fase de recria (15 semanas). Essa equação foi elaborada considerando em sua maioria pintos e galos, o que explicaria os valores contraditórios.

A equação estimou perdas nos valores de EM entre as frações de milho de diferentes qualidades, principalmente devido às variações na sua classificação. Observou-se que os valores das perdas de energia metabolizável (EMp) aumentaram à medida que a densidade do milho piorou. Os resultados corroboram Silva et al. (2008) que encontraram perdas de: 93,71; 200,$76 ; 335,89$ e $161,13 \mathrm{kcal} / \mathrm{kg}$, para o MDA, MDI, MDB e MDT, respectivamente.

Tabela 7. Valor energético e erro padrão da média das frações de milho estratificado com base na matéria natural para frangas de reposição na fase de recria (15 semanas)

\begin{tabular}{lcc}
\hline Frações & \multicolumn{2}{c}{ EMAn $^{*}$} \\
\hline & Ensaio & Rostagno et al. $(2005)$ \\
\hline MDA $^{1}$ & $3467( \pm 49,70)$ & $3347( \pm 10,77)$ \\
MDI $^{2}$ & $3340( \pm 46,85)$ & $3277( \pm 15,51)$ \\
MDB $^{3}$ & $3217( \pm 41,59)$ & $3007( \pm 20,28)$ \\
MDT $^{4}$ & $3385( \pm 97,16)$ & $3248( \pm 9,18)$ \\
\hline
\end{tabular}

"EMAn - Energia Metabolizável Aparente corrigida pelo balanço de nitrogênio $(\mathrm{kcal} / \mathrm{kg})$. ${ }^{1} \mathrm{MDA}$ - milho de densidade alta; ${ }^{2}$ MDI - milho de densidade intermediária; ${ }^{3} \mathrm{MDB}$ - milho de densidade baixa e ${ }^{4} \mathrm{MDT}$ - milho de densidade total, composto de $30 \%$ de MDA, $60 \%$ de MDI e 10\% de MDB. 
As análises de micotoxinas realizadas nas diferentes frações de milho e nas rações experimentais são apresentadas nas Tab. 8 e 9.

Tabela 8. Análises de micotoxinas para as diferentes frações de milho utilizando ensaio ELISA (Enzyme-linked Immunosorbent Assay)

\begin{tabular}{lcc}
\hline $\begin{array}{l}\text { Tipos de } \\
\text { Milho }\end{array}$ & $\begin{array}{c}\text { Aflatoxinas } \\
\left(\mathrm{ppb}^{*}\right)\end{array}$ & $\begin{array}{c}\text { Tricotecenos - T2 } \\
\left(\mathrm{ppb}^{*}\right)\end{array}$ \\
\hline $\mathrm{MDA}^{1}$ & 4,4 & 3,4 \\
$\mathrm{MDI}^{2}$ & 0,9 & 11,9 \\
$\mathrm{MDB}^{3}$ & 2,2 & 13,9 \\
$\mathrm{MDT}^{4}$ & 1,6 & 16,7 \\
\hline
\end{tabular}

${ }^{1}$ MDA - milho de densidade alta; ${ }^{2} \mathrm{MDI}$ - milho de densidade intermediária; ${ }^{3} \mathrm{MDB}$ - milho de densidade baixa e ${ }^{4} \mathrm{MDT}$ - milho de densidade total, composto de $30 \%$ de MDA, $60 \%$ de MDI e $10 \%$ de MDB; ${ }^{*}$ ppb: parte por bilhão.

Tabela 9. Avaliação de micotoxinas nas rações do ensaio de metabolismo

\begin{tabular}{lcc} 
Rações & $\begin{array}{c}\text { Aflatoxinas } \\
\left(\mathrm{ppb}^{*}\right)\end{array}$ & $\begin{array}{c}\text { Tricotecenos - T2 } \\
\left(\mathrm{ppb}^{*}\right)\end{array}$ \\
\hline $\mathrm{RR}+\mathrm{MDA}^{1}$ & 0,3 & 25,0 \\
$\mathrm{RR}+\mathrm{MDI}^{2}$ & 2,7 & 0,0 \\
$\mathrm{RR}+\mathrm{MDB}^{3}$ & 0,0 & 19,5 \\
$\mathrm{RR}+\mathrm{MDT}^{4}$ & 4,3 & 58,3 \\
\hline
\end{tabular}

${ }^{1} \mathrm{RR}+\mathrm{MDA}-60 \%$ da ração referência $+40 \%$ de milho de densidade alta; ${ }^{2} \mathrm{RR}+\mathrm{MDI}-60 \%$ da ração referência $+40 \%$ de milho de densidade intermediária; ${ }^{3} \mathrm{RR}+\mathrm{MDB}-60 \%$ da ração referência $+40 \%$ de milho de densidade baixa e ${ }^{4} \mathrm{RR}+\mathrm{MDT}-60 \%$ da ração referência $+40 \%$ de milho de densidade total, composto de $30 \%$ de MDA, $60 \%$ de MDI e $10 \%$ de MDB; ${ }^{*}$ ppb - parte por bilhão.

De acordo com as tabelas, há presença de baixos níveis de aflatoxinas e tricotecenos (T-2). Recomendações do Laboratório de Análises de Micotoxicológicas (Lamic, 2007) apresentam limites máximos permitidos na alimentação de poedeiras de $10 \mathrm{ppb}$ para aflatoxinas, valor superior ao encontrado nas frações de milho e rações utilizadas no período experimental.

\section{CONCLUSÃO}

Milhos de diferentes qualidades apresentaram grandes variações quanto ao valor energético (EMAn) e ao perfil de aminoácidos digestíveis. A mesa densimétrica pode ser considerada uma importante estratificadora, contribuindo para a melhoria da qualidade dos grãos utilizados na alimentação avícola.

\section{REFERÊNCIAS}

BAIDOO, S.K.; SHIRES, A.; ROBBLEE, A.R. Effect of Kernel density on the apparent and true metabolizable and true metabolizable energy value of corn for chickens. Poult. Sci., v.70, p.2102-2107, 1991.

BRASIL. Ministério da Agricultura, Pecuária e Abastecimento. Portaria $\mathrm{n}^{\mathbf{0}} 845$, de 08 de novembro de 1976. Especificações para a padronização e comercialização interna do milho. Diário Oficial da União - D.O.U., de 08 de novembro de 1976.

CONTE, A.J.; TEIXEIRA, A.S.; BERTECHINI, A.G. Efeito da fitase e xilanase sobre a energia metabolizável do farelo de arroz integral em frangos de corte. Cienc. Agrotec., v.26, p.12891296, 2002.

EMBRAPA-EMPRESA BRASILEIRA DE PESQUISA AGROPECUÁRIA -. Tabela de composição química e valores energéticos de alimentos para suínos e aves. 3. ed. Concórdia: CNPSA, 1991. 97p.

HY LINE. Guia de Manejo Hy Line W-36, 2008. Disponível em: <http://www.hyline.com/ w98s_01.pdf.> Acessado em: 10 mar. 2008.

JANSSEN, W.M.A. European table of energy values poultry feedstuffs. 3.ed. Beekbergen: Spelderholt Center for Poultry Research and Information Services, 1989. 84p.

LAMIC - LABORATÓRIO DE ANÁLISES MICOTOXICOLÓGICAS - Universidade Federal de Santa Maria - RS, Brasil. Tabelas de Resultados, 2007 e Legislação sobre Micotoxinas. Disponível em: <http:// www.lamic.usfm.br>. Acessado em: 20 jan. 2010.

LEESON, S.; SUMMERS, J.D. Effect of adverse growing conditions on corn maturity and feeding value for poultry. Poult. Sci., v.55, p.588-593, 1976.

LIMA, G.J.M.M. Grãos de Alto Valor Nutricional para a produção de Aves e Suínos: oportunidades e perspectivas. In: A PRODUÇÃO ANIMAL NA VISÃO DOS BRASILEIROS. Piracicaba, SP. Anais... SBZ, 2001. p.178-194. 
LOPES, D.C.; FONTES, R.A.; DONZELE, J.L.; ALVARENGA J.C. Perda de peso e mudanças na composição química do milho (Zea mays, L.) devido ao carunchamento. Rev. Bras. Zootec., v.17, p.367-371, 1988.

MATTERSON, L.D.; POTTER, L.M.; STUTZ, N.W. The metabolizable energy of feed ingredients for chickens. Agricul. Experim. Station Rese. Rep., v.7, p.3-15, 1965.

NORVÁEZ-SOLARTE, W.V. Exigências em metionina+cistina para poedeiras leves $e$ semipesadas. Universidade Federal de Viçosa UFV, 1996. 57f. Dissertação (Mestrado em Zootecnia) - UFV.

NOVAK, C.L.; YAKOUT, H.S.; SCHEIDELER, $\mathrm{S}$. The combined effects of dietary lysine and total sulfur amino acid level on egg production parameters and egg components in dekalb delta laying hens. Poult. Sci., v.83, p.977-984, 2004.

NUTRIENT requirements of poultry. 9.ed. Washington: National Academy of Sciences, 1994, 176p.

PEREIRA, C.E. Interação entre densidade específica do milho e aflatoxinas no desempenho de frangos de corte. Universidade Federal de Santa Maria, 2009. 56f. Dissertação (Mestrado em Medicina Veterinária) - UFSM.

POZZA, P.C.; ROCHA, L.D.; NUNES, C.G.V. et al. Valores energéticos do milho e do farelo de soja derterminados com poedeiras na fase de produção. Archives of Veterinary Science, v.11,p.34-39, 2006.

RIBEIRO, M.L.G.; SILVA, J.H.V.; COSTA, F.G.P. Efeito dos níveis de lisina e de proteína sobre os parâmetros de carcaças e teor de proteína dos ovos de codornas. Rev. Bras. Cienc. Avic.(Supl.)., v.4, p.68, 2002.
ROSTAGNO, H.S. Composição de alimentos e exigências nutricionais de aves e suínos (Tabelas Brasileiras), $2^{\mathrm{a}}$ edição, Ed. Impr. Univ. da UFV, Viçosa, 186 p., 2005.

ROSTAGNO, H.S. Disponibilidade de nutrientes em grãos de má qualidade. In: Conferência Apinco 1993 de Ciência e Tecnologia Avícolas, Santos, 1993. Anais... Campinas: FACTA, p. 129-39, 1993.

SAEG, UNIVERSIDADE FEDERAL DE VIÇOSA. Sistema para análises estatísticas e genéticas. Versão 9.1. Viçosa, MG:UFV, 2007. CD-ROM.

SILVA, C.S.; COUTO, H.P.; FERREIRA, R.A. et al.

Valores nutricionais de milho de diferentes qualidades para frangos de corte. Rev. Bras. Zootec., v.37, n.5, 2008.

SILVA, C.S. Composição química e energia metabolizável de milho estratificado pela mesa gravimétria e sua utilização na formulação de ração para frangos de corte. Escola Superior de Agricultura "Luiz de Queiroz". Piracicaba USP, 2009. 102f. Tese (Doutorado em Ciência Animal e Pastagens) - Universidade de São Paulo.

VALÉRIO, S.R.; OLIVEIRA, R.F.M.; DONZELE, J.L. Níveis de lisina digestível em rações mantendo-se ou não a relação aminoacídica, para frangos de corte de 1 a 21 dias de idade, sob condições de estresse por calor. Rev. Bras. Zootec., v.32, p.361-371, 2003. 